\title{
Evaluation of tissue levels of Toll-like receptors and cytokine mRNAs associated with bovine periodontitis and oral health
}

\author{
Ana C. Borsanelli ${ }^{\mathrm{a}}$, David F. Lappin ${ }^{\mathrm{b}}$, Lorenzo Viora ${ }^{\mathrm{c}}$, George King ${ }^{\mathrm{c}}$, David Bennett ${ }^{\mathrm{c}}$, \\ Iveraldo S. Dutra ${ }^{a}$, Marcello P. Riggio ${ }^{\mathrm{b}, *}$

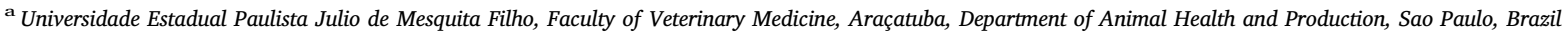 \\ ${ }^{\mathrm{b}}$ Oral Sciences Research Group, Dental School, University of Glasgow, Glasgow, UK \\ ${ }^{\mathrm{c}}$ School of Veterinary Medicine, University of Glasgow, Glasgow, UK
}

\section{A R T I C L E I N F O}

\section{Keywords:}

Bovine

Periodontitis

Toll-like receptors

Cytokines

Innate immune response

\begin{abstract}
A B S T R A C T
Bovine periodontitis is a progressive and purulent infection associated with an anaerobic subgingival biofilm, which induces irreversible damage to the dentition of affected animals. The aetiopathogenesis of the disease is unclear and treatment and control of the disease process in cattle are almost unknown. The aim of this study was to investigate the innate immune response by quantifying expression of Toll-like receptor (TLR) and cytokine genes in gingival tissue samples from cattle with and without periodontitis. Postmortem biopsies of gingival tissues were collected from 20 cattle with periodontitis and 20 cattle with no clinical signs of periodontal lesions. Tissue expression of TLR2, TLR4, TNF- $\alpha, I F N-\gamma, I L-1 \beta$ and $I L-4$ genes were determined using quantitative realtime PCR. Statistically significant increases in mRNA levels encoding TLR2 ( $p=0.025)$, TLR4 $(p=0.037)$, TNF$\alpha(\mathrm{p}=0.025)$, IFN $-\gamma(p=0.014)$, IL-1 $\beta(p<0.001)$ and IL-4 ( $p=0.014)$ were observed in animals with periodontitis when compared to periodontally healthy animals. Increased levels of TLRs and inflammatory cytokines in periodontal tissue indicate an induction of the innate immune response of cattle and suggest that a substantial microbial challenge may be involved in the aetiopathogenesis of bovine periodontitis.
\end{abstract}

\section{Introduction}

Bovine periodontitis is a naturally occurring progressive purulent and infectious process that causes cumulative and readily observed changes in the gums and dentition of slaughtered animals (Borsanelli et al., 2016). The periodontal lesions that develop throughout the productive life of the animals can be characterised by formation of periodontal pockets, gingival recession, loss of clinical insertion and premature loss of teeth (Döbereiner et al., 2000). The complexity of its clinical diagnosis in herds makes it difficult to carry out epidemiological surveys to evaluate its true prevalence. The lack of evidence in the literature suggests that herd owners and veterinarians may not appreciate the potential economic and sanitary significance of periodontal disease in cattle. In its natural occurrence in ruminants, periodontitis has been recorded in sheep (Frisken et al., 1989; Ismaiel et al., 1989; Mccourtie et al., 1990; Riggio et al., 2013) and cattle (Ingham, 2001; Borsanelli et al., 2016). The disease has also been noted in animals raised extensively in tropical biomes in Brazil (Blobel et al., 1987; Borsanelli et al., 2017; Dutra et al., 2000).

In studies on the aetiopathogenesis of bovine periodontitis, Gram- negative anaerobic bacteria have been associated with periodontal lesions, in particular species from the genera Porphyromonas, Prevotella and Treponema (Borsanelli et al., 2015a, 2015b; Dutra et al., 2000). The presence of periodontopathogens is necessary but not sufficient for the development of periodontitis. The exaggerated immune inflammatory response of the host to microorganisms culminates in the destruction of periodontal tissues (Graves, 2008; Preshaw, 2008). Thus, oral health is associated with homeostasis between host and microbiota (Hajishengallis, 2015).

The innate immune system of the host is activated when certain receptors recognise specific structures of molecular patterns associated with aggressive pathogens. These receptors include Toll-like receptors (TLRs), which aid in the early defense of the host against invading agents by activating adapter molecules after binding to their ligands, thereby causing an increase or reduction in the expression of genes that influence the inflammatory response (Akira and Takeda, 2004). The importance of possible agents in the aetiopathogenesis of a disease can be defined by changes in the expression of certain TLRs (Arpaia and Barton, 2013).

Some microorganisms are of recognised importance in the process

\footnotetext{
* Corresponding author at: Glasgow Dental Hospital and School, 378 Sauchiehall Street, Glasgow G2 3JZ, UK.

E-mail address: marcello.riggio@glasgow.ac.uk (M.P. Riggio).
} 
of bone resorption caused by periodontal disease and it is known that levels of TLR2, TLR4, IL-4, IL-1 $\alpha$, TNF- $\alpha$ and IFN- $\gamma$ are increased in human periodontitis (Feng and Weinberg, 2006; Mahanonda and Pichyangkul, 2007). Periodontopathogens can control the expression of a large number of inflammatory cytokines. Porphyromonas gingivalis is able to induce the expression of IL-1 $\beta$, IL-5, IL-6, IL-8, IL-10, IL-13, TNF$\alpha$ and IFN- $\gamma$ while $A$. actinomycetemcomitans stimulates gingival epithelial cells to express IL-1 $\beta$, IL-6, IL-8 and TNF- $\alpha$. Tannerella forsythia induces IL-1 $\beta$ and TNF- $\alpha$ expression and Fusobacterium nucleatum induces the secretion of IL- 8 by epithelial and endothelial cells (Feng and Weinberg, 2006).

Thus, in additional to microbial factors, alterations in the innate immune response have been suggested to play a role in the pathogenesis of periodontitis. To date, there have been no studies of innate immunity in the bovine oral cavity or of its possible involvement in the pathogenesis of bovine periodontal disease.

We hypothesise that bacterial pathogens drive inflammatory cytokines expression by activating specific TLRs, thereby leading to the development of periodontal disease in susceptible animals. In this context, the aim of this study was to evaluate the expression of TLR and cytokine mRNAs in orally healthy cattle and those with periodontitis.

\section{Materials and methods}

\subsection{Sample collecting and processing}

Tissue samples were collected in a local abattoir. Samples of gingival tissue were obtained from around the periodontal pockets of cows with periodontitis and from the gingival margin around PM2-PM3 of animals with a healthy oral cavity. Animals were considered to have periodontitis when both gingival recession and periodontal pockets over $5 \mathrm{~mm}$ in depth were observed.

The collected gingival tissue samples were immediately stored in RNAlater (Sigma-Aldrich, Gillingham, UK) in order to preserve RNA quality. $50 \mathrm{mg}$ of each tissue was then disrupted by homogenisation as described previously (Kennedy et al., 2016b).

\subsection{Isolation of RNA from gingival tissue}

RNA was extracted from homogenised gingival tissue using the RNeasy Fibrous Tissue Mini Kit (Qiagen) and was quantified using a Nanodrop NP-1000 spectrophotometer (Thermo Fisher Scientific, Renfrew, UK).

\subsection{Primer selection and validation}

Primers were selected using the approach described previously (Dolieslager et al., 2013). The bovine mRNA sequences for TLR2, TLR4, IFN- $\gamma$, IL-1 $\beta$, IL-4, TNF- $\alpha$, GAPDH, $\beta$-actin and $18 \mathrm{~S}$ rRNA are shown in Table 1. Primers were validated and amplification efficiency determined using the formula: efficiency $=-1+10(-1 /$ slope $)$ (Dolieslager et al., 2013). The original mRNA level in each tissue was determined using the Comparative Critical Threshold (Ct) method.

\section{4. cDNA preparation}

cDNA was synthesised using the SuperScript ${ }^{\mathrm{TM}}$ First-Strand Synthesis System for RT-PCR (Invitrogen, Paisley, UK) as described previously (Dolieslager et al., 2013).

\subsection{Quantitative PCR}

Quantitative PCR was carried out with SYBR ${ }^{\circledR}$ Select Master Mix (Invitrogen) as described previously (Kennedy et al., 2016b). The following primer annealing temperatures were used: TLR2, TLR4, IL-4, IFN- $\gamma, \beta$-actin, GAPDH and $18 \mathrm{~S}$ rRNA $\left(58^{\circ} \mathrm{C}\right)$; TNF- $\alpha$ and IL- $1 \beta\left(60^{\circ} \mathrm{C}\right)$.
Table 1

Primers used for real-time PCR amplification of bovine TLR and cytokine genes.

\begin{tabular}{|c|c|c|}
\hline Gene & & Sequence $5^{\prime}-3^{\prime}$ \\
\hline \multirow[t]{2}{*}{$18 S$ rRNA } & Forward & GGCCATGATTAAGAGGGGCG \\
\hline & Reverse & CGTCTTCGAACCTCCGACTT \\
\hline \multirow[t]{2}{*}{$\beta$-actin } & Forward & CTAGGCACCAGGGCGTAATG \\
\hline & Reverse & CCGTGCTCAATGGGGTACTT \\
\hline \multirow[t]{2}{*}{ GAPDH } & Forward & CAGGTTGTCTCCTGCGACTT \\
\hline & Reverse & GGTCCAGGGACCTTACTCCT \\
\hline \multirow[t]{2}{*}{$T L R 2$} & Forward & GCAAAATTCTGCTGCGTTGG \\
\hline & Reverse & CCATGCTGTCCACAAAGCAC \\
\hline \multirow[t]{2}{*}{ TLR4 } & Forward & TGCCTGAGAACCGAGAGTTG \\
\hline & Reverse & GGCTGCCTAAATGTCTCAGGT \\
\hline \multirow[t]{2}{*}{$T N F-\alpha$} & Forward & TGCCTTGGCTCAGATGTGTT \\
\hline & Reverse & GAGCGGAGGTTCAGTGATGT \\
\hline \multirow[t]{2}{*}{$I L-1 \beta$} & Forward & TCTTCGAAACGTCCTCCGAC \\
\hline & Reverse & AGCCAGCACCAGGGATTTTT \\
\hline \multirow[t]{2}{*}{$I F N-\gamma$} & Forward & AGATCCAGCGCAAAGCCATA \\
\hline & Reverse & GGCAGGAGGACCATTACGTT \\
\hline \multirow[t]{2}{*}{$I L-4$} & Forward & AATTCCTGGGCGGACTTGAC \\
\hline & Reverse & CAGCGTACTTGTGCTCGTCT \\
\hline
\end{tabular}

GAPDH, 18S rRNA and $\beta$-actin served as housekeeping (reference) genes.

\subsection{Data and statistical analysis}

Analysis of data was conducted using Microsoft Excel followed by GraphPad Prism for Windows (version 5). Gene expression levels were adjusted to the geometric mean of the three housekeeping genes by the $2^{-\delta \mathrm{Ct}}$ method (Livak and Schmittgen, 2001). A non-parametric statistical analysis was carried out using the Mann-Whitney $U$ test, with $p<0.05$ considered to be a statistically significant difference. A parametric age-weighted multivariate analysis was performed on the $\delta \mathrm{Ct}$ data to ascertain the potential effect of the age as a confounding factor in the analysis.

\section{Results}

Gingival tissue samples were obtained from 20 animals with clear signs of periodontal destruction and 20 apparently periodontally healthy animals. The mean depth of the periodontal pocket of the diseased animals was $6.3 \pm 1.7 \mathrm{~mm}$, varying from 5 to $10 \mathrm{~mm}$. Periodontally healthy animals were considered to be those with a subgingival sulcus depth of $<5 \mathrm{~mm}$ and with no evident gingival recession. Although the clinical attachment level of the gingival margin was not recorded precisely, the cement enamel to periodontal pocket base distance was seen to greatly exceed $5 \mathrm{~mm}$. It was observed that the majority of animals with periodontitis ( $>4.5$ years of age; median age of 5.5 years) had complete dentition and healthy animals ( 2 to 3 years of age; median age of 3.0 years) generally presented with the second or third premolar erupting.

Following adjustment to the geometric mean of the three housekeeping gene mRNAs, the levels of mRNA encoding TLR2 $(p=0.025)$ and mRNA encoding TLR4 $(p=0.037)$ were increased in the periodontitis samples compared to the healthy samples (Fig. 1). Data shown are adjusted for the three housekeeping genes. In the age-weighted analysis the difference in TLR4 mRNA levels remained statistically significantly higher in the diseased animals $(p=0.016)$. Differences in TLR2 mRNA levels did not reach statistical significance. Similarly, levels of IL-1 $\beta$ mRNA $(p=0.004)$, IL-4 mRNA $(p=0.014)$, TNF- $\alpha$ mRNA $(\mathrm{p}=0.025)$ and IFN- $\gamma$ mRNA $(\mathrm{p}=0.014)$ were increased in the periodontitis group (Fig. 1). Data shown are adjusted for the three housekeeping genes. In an age-weighted analysis IL-1 $\beta$ mRNA $(p=0.001)$, IL-4 mRNA ( $\mathrm{p}=0.004)$, TNF- $\alpha$ mRNA $(p=0.040)$ and IFN- $\gamma$ mRNA $(\mathrm{p}=0.004)$ were increased in the periodontitis group. 

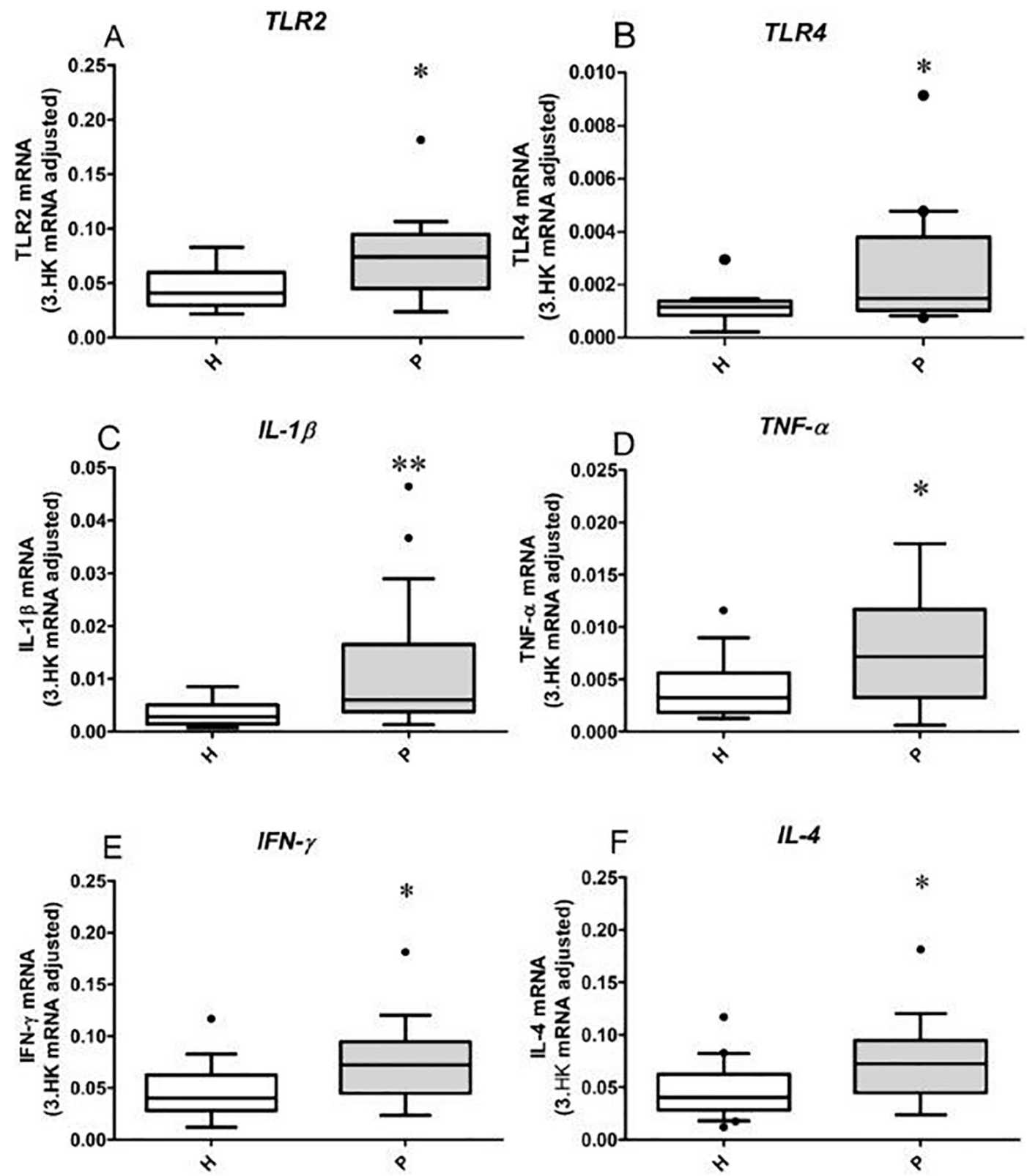

Fig. 1. Box and whisker plots showing gingival tissue levels of (A) TLR2 mRNA, (B) TLR4 mRNA, (C) IL-1 $\beta$ mRNA, (D) TNF- $\alpha$ mRNA, (E) IFN- $\gamma$ mRNA and (F) IL-4 mRNA from the healthy oral cavity $(\mathrm{H} ; n=20)$ and periodontitis-affected mouths $(\mathrm{P} ; \mathrm{n}=20)$ of cattle. Exceptions for TNF- $\alpha(\mathrm{H}, n=19$ and $\mathrm{P}, \mathrm{n}=19)$, IL-1 $\beta$ (H, $n=17$ and $\mathrm{P}, \mathrm{n}=19)$ and TLR2 (H, $n=14$ and $\mathrm{P}, n=16)$. Determinations were rejected because more than one product and/or primer dimers were detected. Outliers are indicated by black dots.

3.HK, three housekeeping genes.

*Significant difference between $\mathrm{P}$ and $\mathrm{H}, p<0.05$.

$* *$ Significant difference between $\mathrm{P}$ and $\mathrm{H}, p<0.01$

\section{Discussion}

In the present study, a statistically significant increase in the expression of mRNAs in the periodontal tissues of animals with periodontitis for TLR2, TLR4, TNF- $\alpha$, and IL- $1 \beta$ was observed when compared to the group of periodontally healthy animals. In this context, it suggests that the occurrence of a substantial challenge to the innate immune system may be a feature of periodontal disease in cattle. In recent years the impact of periodontal disease in other large farm animals such as horses has become more widely recognised, and although the precise aetiology of periodontal disease is yet to be fully elucidated, several key observations are similar to those seen in cattle i.e., the implied involvement of Gram-negative bacteria (Kennedy et al., 2016a) and induction of an almost identical set of innate immune response parameters (Kennedy et al., 2016b) in response to microbial challenge at the periodontium.

In humans, oral microbiota dysbiosis results in changes in the amount of bacteria present in the biofilm and modifies the host-microorganism ratio at levels sufficient to mediate a destructive inflammatory response and bone loss (Hajishengallis, 2014). In this context, periodontal health requires a controlled immune and inflammatory state that maintains host-microorganism homeostasis in the periodontium. It is little known how dysbiosis occurs, if it is a cause or consequence of the disease process and how the dysbiotic microbiota is able to induce an immune inflammatory response that results in pathological bone loss. A major challenge is to understand the role of each 
component of the innate immune system in the host-microbiota relationship in periodontitis (Hajishengallis, 2014).

The innate response of the host represents the first line of immune defense and initially involves the recognition of the microbial components as a warning signal by cells with subsequent production of inflammatory mediators. TLRs are expressed by leukocytes and cells residing in the periodontal environment and are the major signaling molecules through which mammals recognise the infection (Mukhopadhyay et al., 2004), activating the innate response by recognising bacterial components. Thus, each TLR is able to recognise a molecule or subset produced by microorganisms (Mahanonda and Pichyangkul, 2007).

As in man, 10 distinct TLRs have been described in cattle (McGuire et al., 2005). Each of them has its own functional characteristics and an important function against invading pathogens. There is only a limited amount of published information on the expression of bovine TLRs and this is the first report about their role in bovine periodontitis. TLR2 and TLR4 are of importance in periodontitis, recognising pathogens such as A. actinomycetemcomitans, $P$. gingivalis, $T$. forsythia and $F$. nucleatum, and the absence of these receptors results in reduction of alveolar bone loss in P. gingivalis-infected rats (Mahanonda and Pichyangkul, 2007).

TLR2 mRNA and TLR4 mRNA levels were statistically higher in samples from animals with periodontitis when compared to periodontally healthy animals. However, in the present study, the health and disease groups were not age-matched. Consequently, there was a failure to observe increased expression of TLR2 mRNA in the parametric ageweighted analysis, possibly due the skewed nature of the $\delta \mathrm{Ct}$ values for this particular parameter. However, the fact that there was a significant different in median age between the two groups ( 3 years for health, 5.5 years for disease) may have had a bearing on the results obtained for TLR2.

TLR2 and TLR4 are found on the cell surface and can recognise a wide variety of bacterial cell wall components in Gram-positive and Gram-negative bacteria and Mycoplasma sp. (Vasselon and Detmers, 2002). Activation of TLR4 occurs after binding with the lipopolysaccharide of several Gram-negative bacteria (Akira and Takeda, 2004). TLR2 is specifically involved in the recognition of $P$. gingivalis (Hajishengallis et al., 2009), and lipopolysaccharide of Gram-negative periodontal pathogens activates TLR2 more efficiently than TLR4 (Lappin et al., 2011).

The expression of TLR4 in the gingival epithelium (Mori et al., 2003; Ren et al., 2005) and human gingival fibroblasts (Beklen et al., 2014; Wang et al., 2003) reinforces the understanding of its role in periodontal disease. Thus, increased expression of TLR2 and TLR4 in bovine periodontitis may be indicative of high bacterial challenge in the periodontal pocket. Bacteria play a causal role in the pathogenesis of human and animal periodontal disease and hence their potential importance in bovine periodontitis is also expected. Several species of potential periodontopathogens have recently been identified in bovine periodontal lesions by PCR, including spirochaetes and black-pigmented anaerobic bacteria (Borsanelli et al., 2015a; Borsanelli et al., 2015b). We have recently shown that the key genera associated with bovine periodontitis are Prevotella, Fusobacterium and Porphyromonas (Borsanelli et al., 2018), genera which are also associated with human periodontitis. Therefore, it is likely that members of these genera may be important in the activation of TLRs observed in this study. In future studies the relative importance of such species in activating the innate immune could be elucidated by bacterial challenge experiments on cultured bovine cells and measuring TLR activation and cytokine responses.

The excessive production of inflammatory mediators, caused by persistent stimulation of TLRs by periodontopathogens, results in the destruction of periodontal tissue (Mahanonda and Pichyangkul, 2007). After activation of TLRs, an intracellular signaling cascade is stimulated, resulting in the expression of inflammatory cytokines, leukocyte migration and osteoclastogenesis. Cytokines such as IL-1, IL-4, IFN- $\gamma$ and TNF- $\alpha$ play a central role in the inflammatory reaction, bone resorption and loss of connective tissue.

In order to characterise the response of the innate immune system in bovine periodontitis, the current study evaluated expression of IL1- $\beta$, IFN- $\gamma$, TNF- $\alpha$ and IL- 4 mRNA in gingival biopsies of slaughtered animals. Expression levels were all significantly higher in animals with periodontitis irrespective of the difference in the median age between the two groups. A positive correlation was observed between periodontitis and IL-1 $\beta$ mRNA levels. In human patients with periodontitis, IL$1 \beta$ was detected in large quantities at sites with recent bone loss (Lee et al., 1995). This cytokine is also capable of inducing the production of matrix metalloproteinases (Okada and Murakami, 1998). Although it was not an objective of the present study to correlate the findings with different clinical stages of disease, it could be hypothesised that these results may explain the loss of attachment, gingival recession, periodontal pocket formation and suppuration observed in these animals.

Studies in humans, rats and primates have shown that TNF- $\alpha$ expression in gingival tissue and crevicular fluid plays a central role in the inflammatory reaction, production of chemokines leading to leukocyte recruitment, bone loss and loss of connective tissue (Graves and Cochran, 2003; Graves, 2008; Garlet, 2010). In the current study, the TNF- $\alpha$ mRNA mRNA levels were found to be greater in the periodontitis group.

IFN- $\gamma$ mRNA levels were greater in the periodontitis group when compared to the healthy group. IFN- $\gamma$ is associated with the activation of phagocytes and the production of inflammatory cytokines and chemokines (Murphy and Reiner, 2002), with high levels observed in periodontal lesions and severe periodontal diseases (Garlet, 2010). Garlet et al. (2008) further demonstrated that, in rats, IFN- $\gamma$ induces bone resorption in response to A. actinomycetemcomitans.

IL-4 mRNA levels were significantly higher in bovine periodontitis. IL-4 (produced by T cells, mast cells and basophils) regulates the production of some cytokines such as IL- 1 , TNF- $\alpha$ and IL-6, and elevated IL4 levels at sites with periodontitis thus indicate a role for this cytokine and Th2 responses in periodontal lesions (Gemmell et al., 1997).

\section{Conclusions}

In the present study, it was observed that bovine periodontitis is associated with an increase in the expression of several cytokines and TLRs. In other species, recognition of bacteria by TLRs in periodontal tissues initiates a potentially destructive inflammatory response which facilitates progression of periodontal disease. The results of this study suggest a similar pathogenesis in cattle.

An understanding of how oral pathogens interact with host immune responses may provide relevant information on the host-microorganism relationship in periodontitis and assist in the development of preventative and intervention therapies that block the subversive mechanisms of periodontal bacteria in the immune response, thus contributing to the treatment and control of the disease.

\section{Conflicts of interest}

The authors declare that they have no conflicts of interest.

\section{Funding}

This work was supported by the Sao Paulo Research Foundation (FAPESP) through the award of a doctoral scholarship (Process FAPESP2015/06917-9).

\section{References}

Akira, S., Takeda, K., 2004. Toll-like receptor signalling. Nat. Rev. Immunol. 4, 449-511. Arpaia, N., Barton, G.M., 2013. The impact of Toll-like receptors on bacterial virulence strategies. Curr. Opin. Microbiol. 16, 17-22. 
Beklen, A., Sarp, A.S., Uckan, D., TsaousMemet, G., 2014. The function of TLR4 in interferon gamma or interleukin-13 exposed and lipopolysaccharide stimulated gingival epithelial cell cultures. Biotech. Histochem. 89, 505-512.

Blobel, H., Döbereiner, J., Rosa, I.V., Lima, F.G.F., Dutra, I.S., 1987. Bacterial investigations of a periodontal disease, Cara Inchada in Brazilian cattle. Tierärztliche Umschau 42, 152-154.

Borsanelli, A.C., Gaetti-Jardim Júnior, E., Döbereiner, J., Dutra, I.S., 2015a. Treponema denticola in microflora of bovine periodontitis. Pesqui. Vet. Bras. 35, 237-240.

Borsanelli, A.C., Gaetti-Jardim Júnior, E., Schweitzer, C.M., Döbereiner, J., Dutra, I.S., 2015b. Presence of Porphyromonas and Prevotella species in the oral microflora of cattle with periodontitis. Pesqui. Vet. Bras. 35, 829-834.

Borsanelli, A.C., Viora, L., Lappin, D.F., Bennett, D., King, G., Dutra, I.S., Riggio, M.P., 2016. Periodontal lesions in slaughtered cattle in the west of Scotland. Vet. Rec. 179, 652.

Borsanelli, A.C., Gaetti-Jardim Júnior, E., Schweitzer, C.M., Viora, L., Busin, V., Dutra, I.S., 2017. Black-pigmented anaerobic bacteria associated with ovine periodontitis. Vet. Microbiol. 203, 271-274.

Borsanelli, A.C., Lappin, D.F., Viora, L., Bennett, D., Dutra, I.S., Brandt, B.W., Riggio, M.P., 2018. Vet. Microbiol. http://dx.doi.org/10.1016/j.vetmic.2018.03.016.

Döbereiner, J., Dutra, I.S., Rosa, I.V., Blobel, H., 2000. "Cara inchada" of cattle, an infectious, apparently soil antibiotics-dependent periodontitis in Brazil. Pesqui. Vet. Bras. 20, 47-64.

Dolieslager, S.M.J., Lappin, D.F., Bennett, D., Graham, L., Johnston, N., Riggio, M.P., 2013. The influence of oral bacteria on tissue levels of Toll-like receptor and cytokine mRNAs in feline chronic gingivostomatitis and oral health. Vet. Immunol. Immunopathol. 151, 263-274.

Dutra, I.S., Botteon, R.C.M., Döbereiner, J., 2000. Modification of the microflora associated with the periodontal lesions of cara inchada. in calves transferred to a diseasefree area. Pesqui. Vet. Bras. 20, 71-74.

Feng, Z., Weinberg, A., 2006. Role of bacteria in health and disease of periodontal tissues. Periodontol. 2000 40, 50-76.

Frisken, K.W., Laws, A.J., Tagg, J.R., Orr, M.B., 1989. Environmental influences on the progression of clinical and microbiological parameters of sheep periodontal disease. Res. Vet. Sci. 46, 147-152.

Garlet, G.P., 2010. Destructive and protective roles of cytokines in periodontitis: a reappraisal from host defense and tissue destruction viewpoints. J. Dent. Res. 89, $1349-1363$

Garlet, G.P., Cardoso, C.R., Campanelli, A.P., Garlet, T.P., Avila-Campos, M.J., Cunha, F.Q., Silva, J.S., 2008. The essential role of IFN-gamma in the control of lethal Aggregatibacter actinomycetemcomitans infection in mice. Microbes Infect. 10, 489-496.

Gemmell, E., Marshall, R.I., Seymour, G.J., 1997. Cytokines and prostaglandins in immune homeostasis and tissue destruction in periodontal disease. Periodontol. 2000 14, 237-252.

Graves, D.T., 2008. Cytokines that promote periodontal tissue destruction. J. Periodontol. 79, 1585-1591.

Graves, D.T., Cochran, D., 2003. The contribution of interleukin-1 and tumor necrosis factor to periodontal tissue destruction. J. Periodontol. 74, 391-401.

Hajishengallis, G., 2014. Immunomicrobial pathogenesis of periodontitis: keystones, pathobionts, and host response. Trends Immunol. 35, 3-11.

Hajishengallis, G., 2015. Periodontitis: from microbial immune subversion to systemic inflammation. Nature 15, 30-44.

Hajishengallis, G., Wang, M., Liang, S., 2009. Induction of distinct TLR2-mediated proinflammatory and proadhesive signalling pathways in response to Porphyromonas gingivalis fimbriae. J. Immunol. 182, 6690-6696.

Ingham, B., 2001. Abattoir survey of dental defects in cull cows. Vet. Rec. 148, 739-742.

Ismaiel, M.O., Greenman, J., Morgan, K., Glover, M.G., Rees, A.S., Scully, C., 1989. Periodontitis in sheep: a model for human periodontal disease. J. Periodontol. 60, 279-284.

Kennedy, R., Lappin, D.F., Dixon, P.M., Buijs, M.J., Zaura, E., Crielaard, W., O'Donnell, L., Bennett, D., Brandt, B.W., Riggio, M.P., 2016a. The microbiome associated with equine periodontitis and oral health. Vet. Res. 47, 49.

Kennedy, R., Lappin, D.F., Dixon, P.M., Bennett, D., Riggio, M.P., 2016b. Gingival Tolllike receptor and cytokine messenger RNA levels in equine periodontitis and oral health. Equine Vet. J. 49, 294-299.

Lappin, D.F., Sherrabeh, S., Erridge, C., 2011. Stimulants of Toll-like receptors 2 and 4 are elevated in saliva of periodontitis patients compared with heathy subjects. J. Clin. Periodontol. 38, 318-325.

Lee, H.J., Kang, I.K., Chung, C.P., Choi, S.M., 1995. The subgingival microflora and gingival crevicular fluid cytokines in refractory periodontitis. J. Clin. Periodontol. 22, 885-890.

Livak, K.J., Schmittgen, T.D., 2001. Analysis of relative gene expression data using realtime quantitative PCR and the 2(-Delta Delta C(T)) method. Methods 25, 402-408.

Mahanonda, R., Pichyangkul, S., 2007. Toll-like receptors and their role in periodontal health and disease. Periodontol. 2000 43, 41-55.

Mccourtie, J., Poxton, I.R., Brown, R., Whittaker, C.R., Spence, J.A., Aitchison, G.U., 1990. A longitudinal study of the cultivable subgingival anaerobic bacteria isolated from sheep during the development of broken mouth periodontitis. J. Med. Microbiol. 31, 275-283.

McGuire, K., Jones, M., Werling, D., Williams, J.L., Glass, E.J., Jann, O., 2005. Radiation hybrid mapping of all 10 characterized bovine Toll-like receptors. Anim. Genet. 37, 47-50.

Mori, Y., Yoshimura, A., Ukai, T., Lien, E., Espevik, T., Hara, Y., 2003. Immunohistochemical localization of Toll-like receptors 2 and 4 in gingival tissue from patients with periodontitis. Oral Microbiol. Immunol. 18, 54-58.

Mukhopadhyay, S., Herre, J., Brown, G.D., Gordon, S., 2004. The potential for Toll-like receptors to collaborate with other innate immune receptors. Immunology 112 , 521-530.

Murphy, K.M., Reiner, S.L., 2002. The lineage decisions of helper T cells. Nat. Rev. Immunol. 2, 933-944.

Okada, H., Murakami, S., 1998. Cytokine expression in periodontal health and disease. Crit. Rev. Oral Biol. Med. 9, 248-266.

Preshaw, P.M., 2008. Host response modulation in periodontics. Periodontol. 2000 48, 92-110.

Ren, L., Leung, W.K., Darveau, R.P., Jin, L., 2005. The expression profile of lipopolysaccharide-binding protein, membrane-bound CD14, and toll-like receptors 2 and 4 in chronic periodontitis. J. Periodontol. 76, 1950-1959.

Riggio, P.M., Jonsson, N., Bennett, D., 2013. Culture-independent identification of bacteria associated with ovine 'broken mouth' periodontitis. Vet. Microbiol. 166, 664-669.

Vasselon, T., Detmers, P.A., 2002. Toll receptors: a central element in innate immune responses. Infect. Immun. 70, 1033-1041.

Wang, P.L., Ohma, K., Flrjii, T., Oido-Mori, M., Kowashi, Y., Kikuchi, M., Suetsugu, Y., Tanaka, J., 2003. DNA micro array analysis of human gingival fibroblasts from healthy and inflammatory gingival tissues. Biochem. Biophys. Res. Commun. 305, 970-973. 